\title{
A Cultural Approach to Translating Arabic Literary Works with reference to Cairo Trilogy I (Palace of Desire)
}$$
\text { Muhammad K. Assayyed }{ }^{(*)}
$$

Abstract

Different cultures have many different manifestations that represent the various aspects of the society (e.g. traditions, habits, behaviors, etc.). Due to differences across cultures, meanings and concepts vary across divergent cultures, too. The most obvious points of this divergence appear in extralinguistic cultural markers that result in difficulties in rendering meanings and concepts from one language into another. So, this study investigates the challenges inherent in translating culture-specific items in literary contexts and at the same time highlights the adequate strategies followed by the translators to successfully maintain the cultural properties of STs. To this end, the Arabic ST of Mahfouz's Palace of Desire and its English translation are used. Then, a contrastive analysis of ST-TT coupled pairs is carried out to figure out how Arabic cultural signs are transferred into English based on Venuti's model (1995). The findings show that translators should have great sagacity and profound awareness of different culture-specific items in both SL and TL, and that this awareness helps to overcome obstacles in rendering Mahfouz's Palace of Desire.
\end{abstract}

Key words: culture-specific items, literary translation, Mahfouz's Palace of Desire.

\section{Introduction}

Intercultural interaction is now widely recognized as an important aspect of translation. This can, in turn, facilitate the flow of information and knowledge among peoples speaking dissimilar

(*) Teaching Assistant, Translation Program, Faculty of Arts, Sohag University.

This paper is a part of $\mathrm{PhD}$. thesis entitled: "Treatment of Intertextuality in Translating arabic Literature into English: The Case of Naguib Mahfouz". Supervised by Prof. Bahaa el Deen M. Mazeed Faculty of Al- Alsun, Sohag University \& Dr. Dr. Ismail Abdel Ghani Ahmed - Faculty of Arts, Sohag University. 
languages and living in divergent cultures. For the achievement of effective communication, it is of vital importance to move beyond the semantic dimension of the text at hand so as include other factors such as cultural and social reflections. The increasing emphasis on the cultural aspects of translation has led to approaches calling for the treatment of translation as a basically cultural phenomenon. The absence of such recognition might give rise to serious obstacles in conveying the meaning expressed in the original text; accordingly, translation losses might appear. The translator should, thus, guarantee that the TT exhibits the main features of the ST by well integrating it into the new product to create the same effect on TL receivers. This reinforces the idea that the translator has a very challenging task; being the mediator whose main responsibility is to connect two linguistic and cultural worlds, in trying to build a dialogue between texts, to create an equal interchange between different cultures.

One of the problematic areas in translation practice is literature; this is because specialists in literary translation do not merely transfer the meaning of texts but the figurative and aesthetic values that authors intended to enclose. Literature is not an isolated phenomenon, but instead it reflects the social and cultural manifestations of a particular society, e.g. values, attitudes, habits, behaviors, traditions, and ideologies. As a result, a work of literature "is not merely a combination of verbal signs, but a culturally-loaded linguistic system, one that requires a thorough going comprehensive examination before translation is carried out" (Popovic, 1975, p. 5). That is, literary texts are so deeply rooted and firmly fixed in their $\mathrm{SC}$, and thus literary translators probably encounter some troubles in the act of translation; one of which is culture-bound items. It is the task of the translator to come up with an adequate equivalence for these references in the TL. In a nutshell, such an approach has to carry a similar impact and to be meaningful for TRs, otherwise there will be a loss of meaning and a distortion of the message.

\section{Review of the literature}

\subsection{Cultural turn in translation studies}

Interest in the cultural dimension of translation arises from the recognition that "no text is ever produced in a cultural vacuum. 
Texts are made within and in response to a particular context ... texts contain a load of cultural meanings on top of (next to, within) their linguistic meanings" (Delabastita, 1993, pp. 13:14). If, according to this view, texts do not exist in isolation, then the reception of any text is always bound to a broader historical, religious, and social context. The influence of culture on the meaning of texts indicates that "the attitudes and values, the experience and tradition of a people, inevitably become involved in the freight of meaning carried by language", and so "in effect, one does not translate languages, one translates cultures" (Casagrande, 1954, p. 338). The idea is that the translator's job is clearly not confined to the text itself but rather to the text in its cultural context. Mazid (2016) holds the view that "translation can be thought of carrying something from one place to another. This entails that 'meaning' can be picked up from one text, one language, one context/culture to another" (p. 4). For the sake of brevity, not only does the process of rendering involve two languages: SL and TL, but also two cultures: SC and TC.

For the translator, culture is as important as language, and the cultural approach to translation "has begun the process of examining the ways in which translation is nourished by - and contributes to the dynamics of cultural representation" (Simon, 1996, p. 130). Such a development in the field of translation has given more prominence to cultural factors in the theories and processes of translation. In a nutshell, the shift in the mainstream of translation studies from linguistic approaches to cultural, social, and religious ramifications is referred to as the 'cultural turn'. This cultural approach, according to Bassnett (2007), "reflects the cultural turn in other disciplines, which is an inevitable result of the need for greater intercultural awareness in the world today" (p. 23). Seemingly, it becomes a general trend in humanities and social sciences which have been influenced by postmodernist, poststructuralism, deconstruction, postcolonial, and feminist movements, etc. Historically speaking, the "major turning point in the recent history of translation studies occurred when the cultural turn became popular around 1990. The cultural turn in translation studies designates the move towards the analysis of translation from the 
perspective of cultural studies" (Andone, 2002, p. 135). To sum up, the cultural turn, a relatively new approach, is adopted by culturalstudies oriented scholars to signify a theoretical and methodological shift in the domain of translation so as to include cultural, historical, political, economic, and ideological dimensions in addition to linguistic considerations.

\subsection{Culture-bound items in literary translation}

Literary translation comprises the translation of all genres of literature such as novels, short stories, plays, poems, etc. Generally, the purpose of reading literature is to emphasize "the importance of recognizing national similarities, of distinguishing unique differences and of realizing that through the study of great literature one can come to understand and respect systems and ideologies different from one's own" (Neumann \& McDonnell, 1996, p. xiii). If perceived as such, then literary translation is one of the main ways of cross-cultural communication as it introduces all or part of a particular culture to readers from different cultures; accordingly, it makes readers aware of the existence of literary works of other cultures. Nida (1976) stresses the idea that the process of translating literary works "requires a corresponding artistic ability on the part of the translator. The pleasing use of words demands aesthetic sensitivity in the same way that the pleasing arrangement of colors or of three-dimensional space requires aesthetic competence" ( $p$. 65). In order to produce a satisfactory translation of artistic works, having a good command of source and target language is not enough for translators; additionally, they should have a good command of the literary language as well. In connection with this issue, the "stylistic dimension of communication is, of course, of special interest to literary studies, and so it is not surprising that theorists concerned with literary translation have paid considerable attention to the preservation of the stylistic properties of texts" (Gutt, 1991, p. 123). To conclude, the ability to reproduce the style of the original text depends on the degree of similarity between the two languages and two cultures involved.

To establish a practical approach for literary translation, it should be taken in consideration that literary works display various linguistic peculiarities as well as social and cultural aspects of 
humans' lives. Because of their cultural embeddedness, translating literary texts is a task fraught with multiple potential pitfalls; one of which is cultural references. In this context, translators occupy the role of social mediators between two cultures, "since it is necessary to decide on how to translate concepts represented in the SL and TL using different ideas and images and how to translate idiomatic expressions that may carry extra meaning in the translated literary genre" (Lahlali \& Abu Hatab, 2014, p. 23). The issue of translating cultural signs is primarily problematized by the idea that they "create networks of associations which are specific to the culture in which they are rooted" (Ranzato, 2016, p. 57-58). As a consequence, literary works are written and read in light of the familiarity that both authors and readers have of these cultural signs; and so, for successful communication between any two different linguistic codes to take place, readers should be aware of the denotation and connotation of such original cultural signs.

\subsection{Challenges in translating cultural references}

There is a general consensus regarding the possibility of translating CSIs that translators are confused with myriads of potential challenges associated with such items which "can be more problematic for the translator than semantic or syntactic difficulties" (Gonzalez-Cascallana, 2006, p. 123). In his discussion of the problems of non-equivalence between SLs and TLs, Nida (1964) supports this idea, stating that "differences between cultures may cause more severe complications for the translator than do differences in language structure" (p. 130). These problems are even more apparent and complicated for the translator when it comes to languages of different origins or cultures with disparate ideological, political, religious, economic, and educational aspects. For the sake of sufficient clarity, "there are vast cultural differences between a Western language such as English and a Semitic language like Arabic. One cannot translate these languages without paying attention to these cultural differences" (Sofer, 2002, pp. 65:66). These cultural asymmetries might have a significant impact on the flow of communication in given interlingual exchanges, as in translation activities. To put it simply, English and Arabic belong to two different and distant language families; while Arabic is a 
member of the Semitic language family, English belongs to the Indo-European language family. Therefore, in order to produce acceptable translations that can migrate from Arabic to English without noticeable conflicts, social and cultural disparities and their significance should be taken into consideration during the translation process.

Again, CSIs are usually expressed in a text "by means of objects or systems of classification and measurement whose use is restricted to the source culture, or by means of the transcription of opinions and by description of habits equally alien to the receiving culture" (Aixelà, 1996, p. 56). Understanding such items depends upon the assumption that there is a vast body of knowledge shared by the writer and text receivers, and that therefore readers can comprehend the writer's referent. Larson (1998) reports that "one of the most difficult problems facing a translator is how to find lexical equivalents for objects and events which are not known in the target culture" (p. 163). The idea is that some references signifying objects, facts, phenomena, etc. are so deeply rooted in their SC and so specific to the culture and language in which they arise that they have no equivalent in the TC. This phenomenon is called "semantic void or lexical gap" (Gambier, Miriam \& Radegundis, 2004, p. 11). Semantic voids are defined by Dagut (1978) as the "non-existence in one language of a one-word equivalent for a designatory term found in another" (p. 45). In this connection, Shunnaq (1998) argues that in some cases "translator[s] may find certain lexical items in Arabic that have no equivalences in English because the concepts they refer to do not exist in English." (p. 42). In Arabic, for example, there are numerous words that can be used to identify different kinds of camels, and they "conceptualize camels more specifically ... in their cultural groups" (Sternberg \& Sternberg, 2017, p. 369). Surprisingly, in English there is only one word, due to the fact that camels are not part of the English culture.

\section{4. (Un)translatability and cross-cultural readability}

Practically speaking, some translation practitioners think of cultural concepts as untranslatable and sometimes incomprehensible even, since they are associated with a particular culture. Panek (2009), for instance, claims that "with reference to cultural 
differences, it is possible that no equivalent phenomena exist in the TC" (p. 35). Such encounters may probably result in the creation of strangeness or untranslatability of the original text. In fact, the issue of untranslatability is raised by Catford (1965) who mentions that this term "occurs when it is impossible to build functionally relevant features of the situation into the contextual meaning of the [TL] text" (p. 94). Catford also underlines two types of untranslatability, namely linguistic and cultural. The former concerns "the functionally relevant features include some which are in fact formal features of the language of the SL text. If the TL has no formally corresponding feature, the text, or the item, is (relatively) untranslatable" (p. 94). The lack of formal correspondence between two languages might lead to the impossibility of rendering the meaning expressed by an element in one language in the other language. The latter occurs "when a situational feature, functionally relevant for the SL text, is completely absent in the culture of which the TL is a part" (p. 99). In this case, the process of translation becomes impossible because the TL has no adequate equivalent for what is denoted by a concept in the SL. In many cases, cultural references are not familiar to TRs, resulting in the untranslatability of such references and the loss of the ST's impact. Baker (1992) disagrees with this point of view when she confirms that "culturespecific items are not necessarily understandable. It is not the specific items an expression contains but rather the meaning it conveys and its association with culture-specific context which can make it understandable or difficult to translate" (p. 68). Based on this premise, every concept within a language or culture should be more or less translatable, and thus the translation of cultural references is not impossible, but rather a challenging task for translators. This is mainly due to the fact that translators who take up such a task are trying to communicate the cultural effects of STs among two audiences who hold two dissimilar cultural and historical backgrounds.

In order to correctly transmit cultural references to the target audience, it should be taken into account that both bilingualism and biculturalism are important prerequisites for translation competence. Gonzalez-Cascallana (2006) points out that translators can either 
translate cultural concepts literally or replace such instances with "cultural equivalents that are easily recognized by the young target audience" (p. 105). In this connection, the substitution of an SL expression with a TL equivalent is applicable only when both SC and TC have mutual social and cultural conventions. However, if they do not have the same shared meanings and values, substitution will not be efficient. Gonzalez-Cascallana also adds, "literal translation, however, often results in a loss of culture-specific connotations and consequently will always fall flat compared to the ST" (p. 106). It often happens that these cultural expressions cannot be translated literally, since literal translation is always fraught with peril; it might lose or distort their original meaning. Note that although translators have to convey both form and content of original texts, their goal is "to keep the meaning constant", and sometimes "the receptor language form should be changed in order that the source language meaning not be distorted" (Larson, 1998, p. 12). The reason is that it is not always possible that equivalence in both meaning and style can always be retained. Whenever there is a conflict between such traditional notions of form and content, "correspondence in meaning must have priority over correspondence in style" (Nida, 1964, p. 164). In brief, in the translation of cultural markers, translators should focus mainly on conveying the content and message of STs, at the expense of the formal structuring.

\section{Theoretical framework}

\subsection{The phenomenon of culture-specific items}

One of the earliest scholars who attempts to identify the characteristics of cultural references is Finkel (1962) for whom they "stand out from the common lexical context, they distinguish themselves for their heterogeneity, and consequently they require a reinforcement of attention in order to be decoded" (as cited in Ranzato, 2016, p. 53). Cultural elements, according to Newmark (1988), "whether single-unit lexemes, phrases collocations are those which are particularly tide to the way of life and its manifestations that are peculiar to a community" (p. 94). In other words, cultureloaded signs include words and combinations of words denoting 
objects, ideas, and concepts that are truly unique to a given society in which a certain language is utilized. Gambier (2007) remarks that such signs depict various "aspects of everyday life such as education, politics, history, art, institutions, legal systems, units of measurement, place names, foods and drinks, sports and national pastimes, as experienced in different countries and nations of the world" (p. 159). It is worthwhile to note that issues related to cultural asymmetries are discussed by various translation scholars and researchers but by different terms. By way of illustration, Newmark (1988) calls such cultural entities "cultural words" (p. 93), Baker (1992) regards them as "culture-specific concepts" (p. 21), Aixelà's (1996) utilizes the term "culture-specific items", Nord (1997) employs the concept "culturemes" (p. 34), Robinson (1997) uses the terminology "realia" (p. 35), and Gambier (2007) describes them as "culture-specific references" (p. 157). To sum up, the current research study adopts Aixelà's (1996) terminology "culturespecific item" which is defined as follows: "elements of the text that are connected to certain concepts in the foreign culture (history, art, literature) which might be unknown to the readers of the TT" (p. 14). Quite often other synonyms are used to avoid repetition and enhance style.

\subsection{Domestication vs. foreignization}

Domestication and foreignization are two basic concepts introduced into modern TS by Venuti in his influential work "The Translator's Invisibility" (1995), and they provide insights into the process of cultural transmission. For Venuti and Anglophone translation traditions, these concepts are now commonly used to signify two interlingual translation approaches, achieving differing levels of adaptation and literalness between STs and TTs, as employed by translators at the time of translating. Venuti (1998) underlines the importance of domestication and foreignization in tackling "the question of how much a translation assimilates a foreign text to the translating language and culture, and how much it rather signals the differences of that text" (p. 102). In an attempt to briefly distinguish between these two different practices, Shuttleworth and Cowie (2014) report that domestication is used to 
designate the type of translation "in which a transparent, fluent style is adopted in order to minimize the strangeness of the foreign text for TL readers" (pp. 43:44). This approach summarizes the practice of translation in such a way as to assimilate alien and foreign words in STs to TL cultural and linguistic standards with the aim of making TTs easy to be understood by the new readership. Being a method that employs a transparent and fluent style resulting in producing translations that are completely empty of unusual expressions, domestication seems to be oriented towards the requirements of both the TR and the recipient culture. So, to give an example, if a translator decides to render Harry Potter novels into Arabic for the sake of Arab children, s/he will opt for the method of domestication so as to give the Arab children the opportunity to perceive the science fiction existed in the English version of Harry Potter which Arab children did not use to experience in their Arab culture.

The domesticating tendency of the translation practice, according to Venuti, can and ought to be replaced with a very different method called the foreignizing practice. Shuttleworth and Cowie (2014) report that an approach based on foreignization is concerned with "the type of translation in which a TT is produced which deliberately breaks target conventions by retaining something of the foreignness of the original" (p. 59). In a nutshell, the foreignizing method represents a source culture-oriented approach to translation, maintaining the source cultural context in terms of settings, names, etc. This is to be achieved by a non-fluent or heterogeneous translation style designed to highlight the foreign aspects of original texts so as to keep a kind of exotic flavor. For more clarification, a translator might be oriented to the Arabic ST when s/he renders Naguib Mahfouz's Cairo Trilogy into English, to give non-Arab readers the chance to have a tantalizing glimpse of the cultural dimensions of Arabs in general and Egyptians in particular.

\subsection{The translator's invisibility}

Both foreignization and domestication can be examined in terms of the Venutian invisibility which refers to "the extent to which certain translation traditions do not tolerate the often intrusive 
presence of the translator in the translation" (Hatim, 2013, p. 50). Describing translators as being invisible or visible in translated texts depends mainly on the nature of STs and the apparent motivation for translating them as well. On the one hand, domestication, as a mode of translation, contributes to the invisibility of translators in translated texts. A translator can be regarded as invisible when her/his translated text "reads fluently, when the absence of any linguistic or stylistic peculiarities makes it seem transparent, giving the appearance that it reflects the foreign writer's personality or intention or the essential meaning of the foreign text" (Venuti, 1995, p. 1). Succinctly speaking, domesticating practices, where fluency is regarded as the most significant quality for a translation, adapt translated texts to target linguistic and cultural identities, and hence making the translator invisible as if the TT is originally written in the recipient culture and not in the SC. Foreignization has meant a close adherence to the foreign text, a literalism that resulted in "a non-fluent or estranging translation style designed to make visible the presence of the translator by highlighting the foreign identity of the ST and protecting it from the ideological dominance of the target culture" (Munday, 2008, p. 145). Such a method would entail not only a freedom from absolute obedience to target linguistic and textual constraints, but also where appropriate "the importation of foreign cultural forms and the development of heterogeneous dialects and discourses" (Venuti, 2001, p. 242). Accordingly, this practice keeps the visibility of the translator fostering the foreignness of the SL and violating TL norms and standards. In summary, translators can either submit to or resist against the TC dominant aspects. In submitting those aspects, they employ the domestication method, whereas in the case of resistance, they employ the foreignization method making the linguistic and cultural asymmetries between STs and TTs more visible.

\section{Methodology}

\subsection{Data Collection}

For the aims of the present study, the Arabic ST of Mahfouz's Palace of Desire 'Qasr al-Shawq' and its English translation are utilized. The reason behind selecting such a novel is that it is rich in culture-bound items that are obviously specific to 
Arabic and Islamic culture. These references might seem very natural to Egyptians in particular and to Arabs in general since their meanings are known to them and easy to understand. But the difficulty arises when translators try to render these socio-cultural elements into English. The examples below illustrate translation challenges arising from transferring these items into English. Each ST is followed by its English translation so that readers could have better access to the corresponding analysis.

\section{Analysis and Discussion}

To give a concrete sense of how culture-specific items work in the context of Mahfouz's Palace of Desire, consider the following examples:

\section{Example 1}

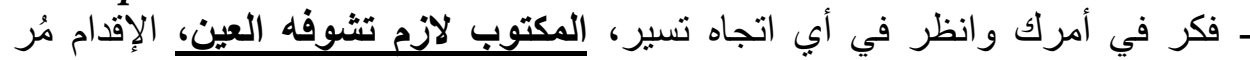

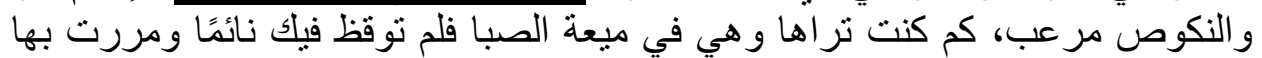

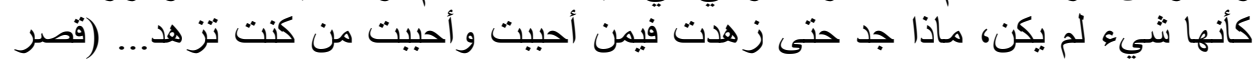

\section{English translation}

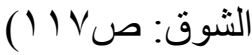

Think about your position and consider which way to go. What's fated to happen will become manifest. To advance is bitter and to withdraw terrifying. You used to see her all the time when she was a fresh young thing. She awakened nothing in you then. You passed by her as though she did not exist. What new developments has there been to cause you to shun the ones you loved and love the one you shunned? (Palace of Desire, p. 92)

\section{Analysis \& Discussion}

The underlined linguistic extract المكتوب لازم تشوفه العين is a culturally-loaded signifier. The value of this extract cannot be understood without linking it to its prior context, i.e. the following

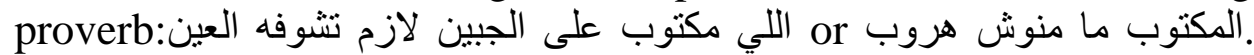
Broadly speaking, this proverb is widely used in informal Arabic, and it means whatever is destined to happen will be fulfilled. Such proverbs "contain a lot of common sense, experience, wisdom, and truth, and as such they represent ready-made traditional strategies in oral speech acts and writings from high literature to the mass 
media" (Meider \& Dundes, 1994, p. 119). From a translation point of view, a proverb is usually impossible to be translated literally because its meaning is not built word by word, but it is a noncompositional phrase which is learned, stored, and recycled as a single item. Thus, when it is said المكتوب لازم تشوفه العين (lit. what is written on the brow will inevitably be seen by the eye); it is actually has nothing to do with the brow or the eye. Although the translators have successfully conveyed the message of the original text as what's fated to happen will become manifest, their rendering does not enjoy the status of being a proverb in English. In this way, the message of the Arabic proverb المكتوب لازم تشوفه العين is semanticized in English. This is due to the belief that items which have various connotations in one language may not have the same emotive associations in another. Divergent languages ordinarily reflect dissimilar connotations and associations of feeling due to the asymmetries in cultural roots. In fact, the process of translating cannot be done precisely without comprehending its invisible/contextual dimensions. As an attempt to accurately transfer the proverb المكتوب لازم تشوفه العين, the translators must consider the idea that this proverb should be substituted for another. That substitution is made not on the basis of the linguistic aspects in the original expression, nor on the basis of a corresponding or similar image contained in the expression, but on the function of the proverb. So, the Arabic proverb المكتوب لازم تشوفه العين should be replaced by a TL proverb that serves the same purpose in the TL culture, and the process involves the substitution of SL sign for TL sign. In conclusion, although the proverbial message of the phrase المكتوب لازم تشوفه العين is relayed literally, the translators have failed to call up the familiar English proverbs there is no flying from fate or there is no fence against ill fortune, which semiotically fit the original context.

\section{Example 2}

ـ تحسر إبر اهيم الفار على العصر الذهبي للنحاس على أيام الحرب، فقال لهم بلسان ثقيل

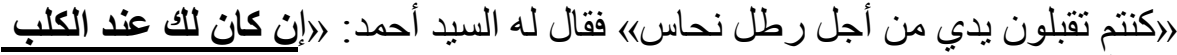

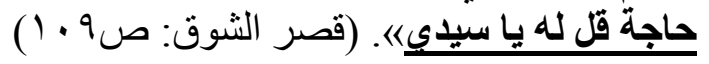




\section{English translation}

Ibrahim al-Far lamented the passing of the copper trade's golden age, during the war. With a thick tongue he told them, "Back then you kiss my hand to get a pound of copper". Al-Sayyid Ahmad commented, "When you need something from a dog, call him 'mister". (Palace of Desire, p. 86)

\section{Analysis \& Discussion}

The last part of the previous example, i.e. إن كان للك عند الكلب entertains a high degree of frequency of use in colloquial Arabic; it roughly means that if you want something from someone else, call him my master. Like other cultural signs, Arabic readers can easily grasp the relation here and what it means to mention إن كان للك عند الكلب حاجة قل له يا سيدي in the context of the novel. In translation, however, this relation and the implications of this sign might not be maintained without using the appropriate translational technique. It is conspicuous that the translators are not إن كان لك عند implication of the cultural specificity of the imare الكلب حاجة قل له يا سيدي different ways of perception which do exist between different peoples, languages, and cultures. Accordingly, they fail to render this part meaningfully; they transfer it literally as when you need something from a dog, call him mister. In this connection, Dickins, Hervey, and Higgins (2017) argue that the use of literal translation might cause problems, since "meanings are not found exclusively in the words listed individually in the dictionary .... it very often arises from the fact that exact synonymy between ST words and TL words is relatively rare" (pp. 127:128). On this basis, the use of literal translation does not give the exact meaning of إن كان للك عند الكلب حاجة قل له يا سيدي, since in English there is no socio-cultural background for this reference; thus, English readers cannot understand the denotative and connotative nuances of the Arabic expression. Had the translators paraphrased such an expression or substituted it with a cultural equivalent, it would be much better than this rendering. In summary, إن كان للك عند الكلب حاجة قل له يا سيدي can be translated idiomatically as call the bear "uncle" till you are safe across the bridge.

\section{Example 3}




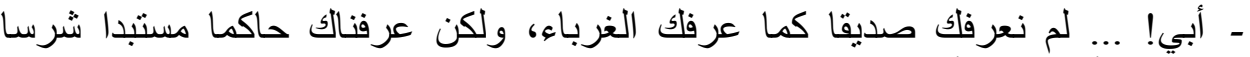

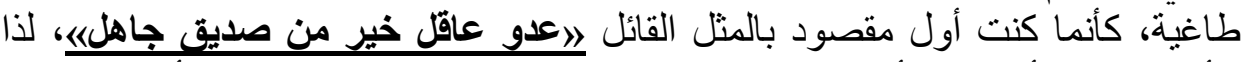

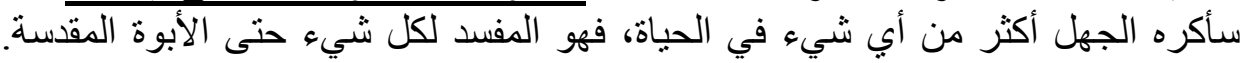

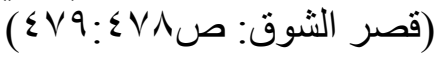

\section{English translation}

Father! ... we've never known you as a friend the way outsiders do. We've known you as a tyrannical dictator, a petulant despot. The saying 'An intelligent enemy's better than an ignorant friend' might well have been coined for you. For this reason, I hate ignorance more than any other evil in life. It spoils everything, even the sacred bond of fatherhood. (Palace of Desire, p. 373)

\section{Analysis \& Discussion}

The underlined segment عدو عاقل خير من صديق جاهل is often used in modern standard Arabic, but it is rarely used informally. This commonly quoted phrase means that foolish or stupid friends are more dangerous than intelligent enemies. By adopting the strategy of literal translation, the translators render the phrase عدو عاقل خير من as an intelligent enemy's better than an ignorant friend. As can be seen, this literal translation can maintain the original form and image of the Arabic proverb without causing confusion in meaning. Therefore, in terms of translating fixed terms, some proverbs could be translated literally. It is beyond dispute that this rendering, i.e. an intelligent enemy's better than an ignorant friend is a preferred version of translation because it fulfills the function of communicative translation and keeps the original flavor of the Arabic construction, i.e. عدو عاقل خير من صديق جاهل. This strategy, though, is not very viable in Arabic due to the cultural differences and the divergent historical affiliations of the two languages. In brief, such kinds of proverbs as عدو عاقل خير من صديق جاهل can be transferred through the employment of literal translation. The most significant point of literal translation, here, lies in the function of retaining the full flavor of the Arabic intertext عدو عاقل خير من صديق جاهل Interestingly, this rendition embodies two strategies: the first communicatizes the proverb's semiotic value by calling up an equivalent sign, namely an English proverb that has a similar function, whereas the second semanticizes the proverb's semiotic value by opting for a literal translation. 
Example 4

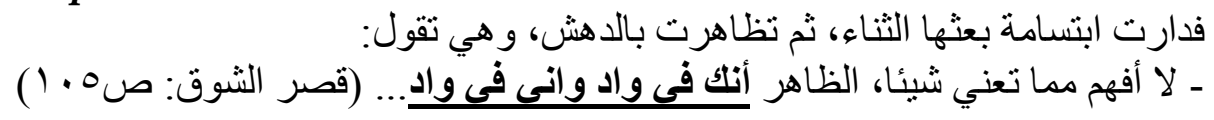
English translation

She hid the smile his praise had inspired and pretended to be astonished as she said, "I absolutely do not understand what you mean. It's clear that we're mountains apart...." (Palace of Desire, p. 101)

\section{Analysis \& Discussion}

The underlined linguistic construction أنك في واد و أني في واد in the example above may represent a mammal task to translators. The speaker utilizes this construction in order to be intertextualized with the metaphor which reads as follows: أنا في واد وانت في واد. This metaphor presents a semantic richness as well as a robust mode of expression. It entertains a high degree of frequency of use in informal Arabic, and it literally means that you are in a valley, and I am in a valley. Here, the speaker pretends not to comprehend what Al-Sayyid Ahmad means when he tells her she is like a puzzle. Subsequently, lack of mutual comprehension makes them like people in divergent places with large distances separating them without any medium of communication. Although the two speakers are physically in the same place, Zanuba says أنك في واد و اني في واد. In as much as the translation of أنك في واد وأني في واد is concerned, it can be said that in the translation of such segments which have a comparable pragmatic effect in the TC, the domestication strategy can be employed successfully. Shuttleworth and Cowie (1997) describe domestication as a type of translation "in which a transparent, fluent style is adopted in order to minimize the strangeness of the foreign text for TL readers" (pp. 43:44). By applying the strategy, the translators render أنك في واد وأني في واد into English as we are mountains apart. Obviously, both the ST and TT utilize geographical features. Yet, each one selects a specific spot. While Arabic involves valley images, English highlights mountain imagery. The result is conveying the function of the metaphor inherent in أنك في واد وأني في واد adequately to the target audience. To repeat, the translators assimilate the phrase أنك في واد وأني في واد 
English linguistic and cultural identities with the aim of making the TT easy to be understood by the new readership. Therefore, they seem to be oriented towards the requirements of both the TR and the recipient culture. In point of fact, the translators resorted to the أنك في واد can be confusing to English readers who are not acquainted with such expressions. In this respect, Carbonell (2004) indicates that "the translator largely prepares the ground for the reader's interpretation, and not merely through a change of linguistic code" (p. 27). In summary, the domesticating translation involves a great deal of cultural approximation and transposition.

\section{Example 5}

$$
\begin{aligned}
& \text { التفت ياسين التفاتة سريعة لحظ بها جميل الحمزاوي ومن معه، ثم قرب الكرسي من } \\
& \text { المكتب، و استجمع شجاعته، قائلًا: }
\end{aligned}
$$

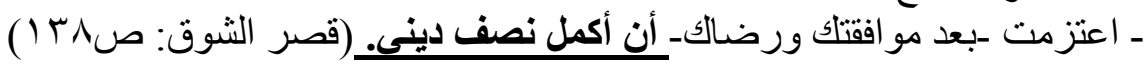

\section{English translation}

Yasin glanced around quickly at Jamil al-Hamzawi and the customers. Then he brought his chair closer to the desk and, summoning all his courage, and said, "I've decided, with your consent and approval, to perfect my religious observance by marrying". (Palace of Desire, p. 108)

\section{Analysis \& Discussion}

The last part of the previous example, i.e. أن أكمل نصف ديني may present translation hurdles. Like other authors, Mahfouz depends on his readers' identification and comprehension of such intertexts to connect his text with the religious context from which it is taken, thus opening his text to different interpretations. It goes without saying that there is no need to spell out such a presumably wellknown context; and hence, the analysis will jump directly to discuss the translation of أن أكمل نصف ديني. Yet, a mere mention of the prophetic Hadith where this specific reference emerges is deemed

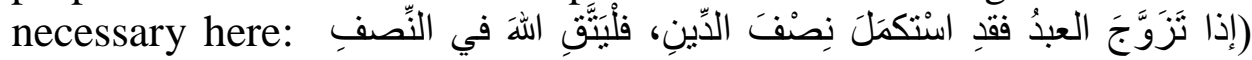
(الباقي). Basically, this saying is widely quoted in informal Arabic and literally means to complete half of my religion. It is used to encourage Muslims to get married once they are capable physically أن أكمل نصف and financially to do so. Regarding the translation of 
ديني, the use of literal translation cannot reflect the various implications of this reference, and so the original meaning might be lost or distorted. To completely discern this expression, the translators have gone beyond the linguistic structure and have had some insights into what the linguistic units may carry in terms of other perspectives. Therefore, they provide ideational equivalence by adopting the strategy of paraphrase during translation process; they render the intertext أن أكمل نصف ديني as to perfect my religious observance by marrying. For the sake of sufficient clarity, 'marriage' in the Islamic culture integrates Muslims' faith and corrects their manner by protecting them against starting or having unlawful relations, and thus the translators add the word marrying, which is not directly written in the original text but rather inferred from the expression أكمل نصف ديني, in their translation to illustrate the intended meaning. In a nutshell, by means of paraphrasing certain lexis, the translators tend to overcome linguistic and cultural gaps between the two languages and the two cultures involved. In this respect, Shuttleworth and Cowie (1997) report that Dryden describes paraphrase in translation as "translation with latitude, where the author is kept in view by the translator, so as never to be lost, but his words are not so strictly followed as his sense" (p. 121). However, this strategy results in a loss of the exact meaning. The translators have sacrificed brevity for maintaining the same meaning of أن أكمل نصف ديني. Actually, there is a general agreement amongst scholars that the procedure of paraphrasing might lead to some loss of certain features of meaning, as it "does not have the status of a lexical item and therefore cannot convey expressive, evoked, or any kind of associative meaning" (Baker, 1992, p. 40). Related to these translation losses is that the significance of marriage as "half one's religious devotion" is lost in the English translation.

\section{Conclusion}

A significant aspect of Mahfouz's language in the Trilogy is its rich variety of cultural information-bearing concepts that pervade his characters' conversations, meditations, and descriptions. These concepts are natural and easy to comprehend by native Arabic speakers. Nevertheless, when taking translation into account, 
difficulties may appear in the English text. In general, the frequent usage of culture-specific items in literary contexts causes tremendous difficulties for translators. When the author refers implicitly or explicitly to such items, he has in mind that his TRs will react to these expressions and will appreciate them, because of their previous knowledge and awareness of the SL culture. It is this kind of previous knowledge and awareness that causes problems to the translators of literary works particularly from Arabic to English and vice versa, since both languages have completely dissimilar cultural backgrounds. Here, the translators are required to exert all the necessary efforts to transfer all references into the TL relying on their knowledge of the world of the ST and their competence. When the source from which such cultural markers are taken is well known, the element becomes easier to be identified by SL readers. Nevertheless, the problem of translation is still there particularly if some cultural markers are absent from the TL. This is because the cultural signs employed by Mahfouz are not mere linguistic or literary items, but they are cultural units that occupy very important situational and contextual positions; they have to be interpreted in light of semiotics to decipher their denotative and connotative values. In short, the lack of congruency between the two different cultural concepts adds to the problems encountering the translators. Unless translators have solid foundation of the culture of both source and target languages, they are most likely to fail in deciphering the intended meaning. As a result, the translator's crosscultural awareness and open-minded comprehension of how languages work across cultures are necessarily required. Moreover, the socio-cultural importance that some Arabic cultural references have is inevitably lost in translation, unless there is an equivalent in the TL. In the absence of such an equivalent the translators make attempts to reproduce the alienating influence of the ST through alternative means. What seems to be prioritised is maintaining the meta-narrative quality of the ST, even when the exact examples do not come through. 


\section{References}

Aixelà, J. (1996). Culture-specific items in translation. In R. Alvarez \& M. Carmen-Africa Vidal (Eds.), Translation, power, subversion (pp. 52-78). Clevedon: Multilingual Matters LTD.

Andone, O. (2002). Gender issues in translation. Perspectives: Studies in Translatology, 10(2), 135-150.

Baker, M. (1992). In other words: A coursebook on translation. London: Routledge.

Bassnett, S. (2007). Culture and translation. In P. Kuhiwozak \& K. Littau (Eds.), A companion to translation studies (pp. 13-23). Clevedon: Multilingual Matters LTD.

Carbonell, O. (2004). Exoticism, identity and representation in

Western translation from Arabic. In S. Faiq (Ed.), Cultural encounters in translation from Arabic (pp. 26-39). Clevedon: Multilingual Matters LTD.

Casagrande, J. (1954). The ends of translation. International Journal of American Linguistics, 20(4), 335-340.

Catford, J. (1965). A linguistic theory of translation. Oxford: Oxford University Press.

Delabastita, D. (1993). There's a double tongue: An investigation into the translation of Shakespeare's wordplay, with special reference to Hamlet. Amsterdam: Rodopi.

Dickins, J., Hervey, S. \& Higgins, I. (2017). Thinking Arabic translation $\left(2^{\text {nd }}\right.$ ed.). London and New York: Routledge.

Gambier, Y. (2007). Doubts and directions in translation studies. Amsterdam: John Benjamins Publishing Company.

Gambier, Y., Miriam, S. \& Radegundis, S. (2004). Doubts and directions in translation studies. The Netherlands: John Benjamins.

Gonzalez-Cascallana, B. (2006). Translating cultural intertextuality in children's literature. In I. Coillie \& W. Verschueren (Eds.), Children's Literature Translation (pp. 97-110). Manchester: St. Jerome Publishing.

Gutt, E. (1991). Translation and relevance: Cognition and context. Oxford: Basil Blackwell. 
Hatim, B. (2013). Teaching and researching translation. Harlow: Pearson.

Hutchins, W., Kenny, L. \& Kenny, O. (Trans.). (1991). Palace of Desire. Cairo: The American University in Cairo Press.

Lahlali, M. \& Abu Hatab, W. (2014). Advanced English-Arabic translation: A practical guide. Edinburgh: Edinburgh University Press Ltd.

Larson, M. (1998). Meaning-based translation: A guide to cross equivalents. Lanham: University Press of America.

Mahfouz, N. (1956). Bein al-Qasrayn. Cairo: Dar Al-Shorouk.

Mazid, B. (2016). World, text and translation: Translation as metatext (The case of Rupert Brooke's Menelaus and Helen). Retrieved January 1, 2018, from https://dokubook.com/download/world-textandtranslationpdf_5a02db93d64ab 2bbbdb60550pdf

Meider, W. \& Dundes, A. (1995). The Wisdom of many: Essays on the proverb. New York: Garland.

Munday, J. (2008). Introducing translation studies: Theories and application $\left(2^{\text {nd }}\right.$ ed.). London and New York: Taylor \& Francis Group.

Neumann, B. \& McDonnell, H. (1996). Teaching the short story: A guide to using stories from around the world. Urbana: National Council of Teachers of English.

Newmark, P. (1988). A textbook of translation. Hertfordshire: Prentice Hall International.

Nida, E. (1976). A framework for the analysis and evaluation of the theories of translation. In R. Brisilin (Ed.), Translation application and research (pp. 47-91) New York: Gardener Press.

Nida, E. A. (1964). Toward a science of translating with special reference to principles and procedures involved in Bible translating. Leiden: E.J. Brill.

Nord, C. (1997). Translating as a purposeful activity: Functionalist approaches explained. Manchester: St. Jerome.

Panek, M. (2009). Subtitling humor: The analysis of selected translation techniques in subtitling elements containing humor. Grin Verlag: Heidelberg. 
Popovic, A. (1975). Dictionary for the analysis of literary translation. Edmonton, Alta: University of Alberta Press.

Ranzato, I. (2016). Translating culture specific references on television: The case of dubbing. London and New York: Routledge.

Robinson, D. (1997). Becoming a translator: An accelerated course. London: Routledge.

Shunnaq, A. (1998). Problems in translating Arabic texts into English. In A. Shannaq, C. Dollerup \& M. Saraireh (Eds.), Issues in translation (pp. 33-52). Jordan: Irbid National University.

Shuttleworth, M. \& Cowie M. (1997). Dictionary of translation studies. New York: Routledge.

Simon, S. (1996). Gender in translation: Cultural identity and the politics of transmission. London and New York: Routledge.

Sofer, M. (2002). The translator's handbook. Rockville \& Maryland: Schreiber Publishing.

Sternberg, J. \& Sternberg, K. (2017). Cognitive psychology $\left(7^{\text {th }}\right.$ ed.). Boston: Cengage Learning.

Venuti, L. (1995). The translator's invisibility: A history of translation. New York: Routledge.

Venuti, L. (1998). The scandals of translation: Towards an ethics of difference. London and New York: Routledge.

Venuti, L. (2001). Strategies of translation. In M. Baker (Ed.), Routledge encyclopedia of translation studies (pp. 240-244). London and New York: Routledge. 